\title{
INFLUENCE OF THERMAL TREATMENT UNDER VARIOUS OXYGEN PRESSURES ON THE ELECTRONIC PROPERTIES OF CERAMICS AND SINGLE CRYSTALS OF PURE AND TIN-DOPED INDIUM OXIDE
}

\author{
SHIJIE WEN, G. CAMPET and J. PORTIER \\ Laboratoire de Chimie du Solide du CNRS, Université de Bordeaux I, 351 cours de la libération, \\ 33405 Talence cedex (France),
}

(Received April 16, 1991; in final form April 29, 1991)

The different electronic behaviors of pure and tin-doped indium oxides with various thermal treatments under high and low oxygen pressure are discussed on the basis of the evolution of the band energy diagram. A critical concentration of "active oxygen vacancies" associated with donor centers is necessary to achieve high electronic mobility in ITO (Indium Tin Oxide).

\section{INTRODUCTION}

Thin films based on tin oxide, indium oxide, and zinc oxide exhibit high transmittance in the visible, high reflectance in the infra-red, and nearly metallic conductivity. Among them, indium oxide (IO) and tin-doped indium oxide (ITO) films have received special attention due to their slightly superior electrical and optical properties $^{1,2}$.

The effect of heat treatment under various oxidizing or reducing atmospheres has been investigated by several authors ${ }^{1,3-10}$. However, the respective contributions on some basic parameters $(\sigma, \mu, n, \ldots)$ of donor centers arising from appropriate tin doping:

$\left(1-\frac{\varepsilon}{2}\right) \mathrm{In}_{2}^{3+} \mathrm{O}_{3}+\frac{\varepsilon}{2} \mathrm{Sn}^{2+} \mathrm{O}+\frac{\varepsilon}{2} \mathrm{Sn}^{4+} \mathrm{O}_{2} \longrightarrow \mathrm{In}_{2-\varepsilon}^{3+} \mathrm{Sn}_{\varepsilon}^{4+} \mathrm{O}_{3}\left[\mathrm{e}^{-}(\mathrm{CB})\right]_{\varepsilon}$

(with $\mathrm{e}^{-}(\mathrm{CB})$ designating the conduction-band electrons), or from "active" oxygen vacancies:

$\mathrm{In}_{2-\varepsilon}^{3+} \mathrm{Sn}_{\varepsilon}^{4+} \mathrm{O}_{3}\left[\mathrm{e}^{-}(\mathrm{CB})\right]_{\varepsilon} \longrightarrow \mathrm{In}_{2-2 \varepsilon}^{3+} \mathrm{Sn}_{\varepsilon}^{4+} \mathrm{O}_{3-\varepsilon^{\prime}}\left[\mathrm{e}^{-}(\mathrm{CB})\right]_{\varepsilon+2 \varepsilon^{\prime}}+\frac{\varepsilon^{\prime}}{2} \mathrm{O}_{2}$ 
has not yet been clearly established. This lack of understanding can be explained by the fact that only limited information is available on the fundamental material properties of undoped or tin-doped single crystals and ceramics ${ }^{1-10}$.

We discuss, in this paper, the different behavior of $\operatorname{In}_{2} \mathrm{O}_{3}$ and $\mathrm{SnO}_{2}$ doped $\operatorname{In}_{2} \mathrm{O}_{3}$ ceramics and single crystals under thermal poor and rich oxygen treatments. The discussion is aimed at a better understanding of the respective influence of the two types of donors centers, described above in relations (1) and (2), on the electrical properties of ITO. The influence of compacity, grain size, and grain boundary on the electrical properties have also been studied and will be reported elsewhere for the sake of clarity ${ }^{11}$.

\section{PREPARATIONS}

\section{II.1 Crystal Growth}

$\mathrm{In}_{2} \mathrm{O}_{3}$ and $\mathrm{Sn}$-doped $\operatorname{In}_{2} \mathrm{O}_{3}$ single crystals were grown by the flux method. We varied the relative amounts of indium oxide and tin oxide, keeping the total weight constant $(3 \mathrm{~g})$; the mixture was intimately mixed with a flux made of $3 \mathrm{~g} \mathrm{~B}_{2} \mathrm{O}_{3}$ and $37.5 \mathrm{~g}$ $\mathrm{PbO}$. The starting materials were Alfa Products (reagent-grade). The powders were ground and mixed mechanically, then placed into a platinum crucible (about 20 $\mathrm{cm}^{3}$ ) covered with a platinum lid. The crucible was placed into a ceramic crucible and gradually heated in air at a rate of $60^{\circ} \mathrm{C} / \mathrm{h}$ until the final temperature $\left(1320^{\circ} \mathrm{C}\right)$ was reached). It was then maintained at this temperature for $6 \mathrm{~h}$ to ensure the complete dissolution of the oxides. The temperature was then reduced at the rate of $5^{\circ} \mathrm{C} / \mathrm{h}$ down to $850^{\circ} \mathrm{C}$. By boiling the platium crucible in aqueous $\mathrm{HNO}_{3}$, the flux products were dissolved. $\mathrm{In}_{2} \mathrm{O}_{3}$ and $\mathrm{Sn}$-doped $\mathrm{In}_{2} \mathrm{O}_{3}$ single crystals were thus obtained in the form of platelets with a maximum dimension of $10_{\mathrm{mm}} \times 10_{\mathrm{mm}}$ $\times 2$ mm.

The crystals were studied by x-ray diffraction. Both $\operatorname{In}_{2} \mathrm{O}_{3}$ and Sn-doped $\operatorname{In}_{2} \mathrm{O}_{3}$ single crystals have the expected bixbyite type structure. Spectro-chemical analysis indicated that metallic lead was the only significant impurity present with a concentration of the order of $0,05 \%$ (weight).

\section{II.2 Ceramic Preparation}

$\mathrm{In}_{2} \mathrm{O}_{3}$ ceramic samples were first prepared by sintering pellets in air at different temperatures $\left(900^{\circ} \mathrm{C}, 1000^{\circ} \mathrm{C}, 1100^{\circ} \mathrm{C}, 1200^{\circ} \mathrm{C}, 1300^{\circ} \mathrm{C}\right)$ during $24 \mathrm{~h}$ with a raising rate of $100^{\circ} \mathrm{C} / \mathrm{h}$ and a cooling rate of $100^{\circ} \mathrm{C} / \mathrm{h}$.

\section{II.3 Thermal Treatments}

Annealing treatments were performed at $800^{\circ} \mathrm{C}$ for $24 \mathrm{~h}$ (raising and cooling temperature rate of $\left.100^{\circ} \mathrm{C} / \mathrm{h}\right)$ either under vacuum $\left(\mathrm{P}_{\mathrm{O} 2}=10^{-5}\right.$ bar $)$ or under elevated oxygen pressure $\left(\mathrm{P}_{\mathrm{O} 2}=200\right.$ bar $)$. 


\section{HALL EFFECT MEASUREMENTS}

Accurate values of mobility and carrier concentration were obtained using an a.c. Van der Pauw method (1.2T magnetic field). An In-Ga eutectic ensured electrical contacts. The dimensions of samples were typically $2_{\mathrm{mm}} \times 2_{\mathrm{mm}} \times 0.5_{\mathrm{mm}}$ for crystals and $5_{\mathrm{mm}} \times 5_{\mathrm{mm}} \times 0.5_{\mathrm{mm}}$ for ceramics.

\section{RESULTS AND DISCUSSION}

According to previous results, the samples are, as expected, n-type degenerate semiconductors with metallic electrical properties ${ }^{11}$.

Although electrical measurements have been carried out down to $4 \mathrm{~K}$, we will focus here, for sake of clarity, on room temperature electrical evaluation of the different samples as illustrated in Fig. 1, 2, and 3. All of the results reported here are average values obtained from the measurements performed with various samples; usually three samples of each type were checked.

Fig. 1, dealing with $\operatorname{In}_{2} \mathrm{O}_{3}$ ceramics, shows that the carrier concentration increases as the sintering temperature (see II.2) increases. Such an evolution should be correlated, not only with an increase of ceramic compacity ${ }^{11}$, but also with an increase in the concentration of the active oxygen vacancies: Indeed, relation (2) also applies for pure $\operatorname{In}_{2} \mathrm{O}_{3} ; \varepsilon^{\prime \prime}$ increases with the sintering temperature because

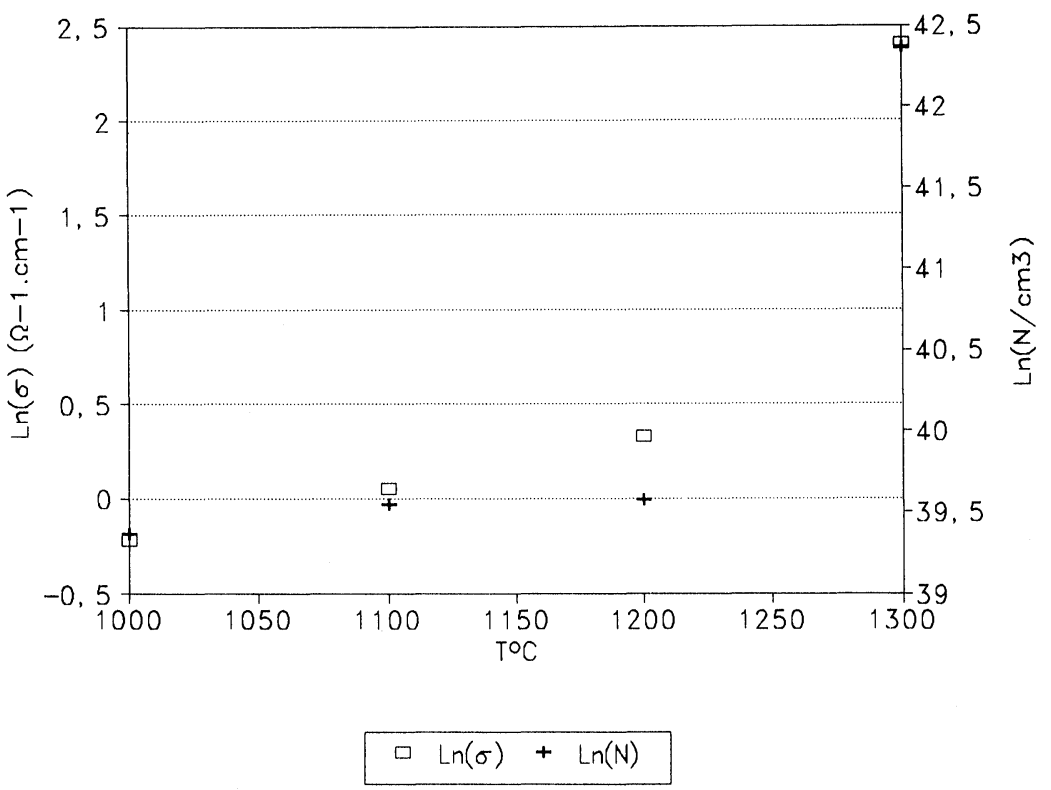

FIGURE 1 Electrical properties of $\mathrm{In}_{2} \mathrm{O}_{3}$ ceramics as a function of the sintering temperature. 


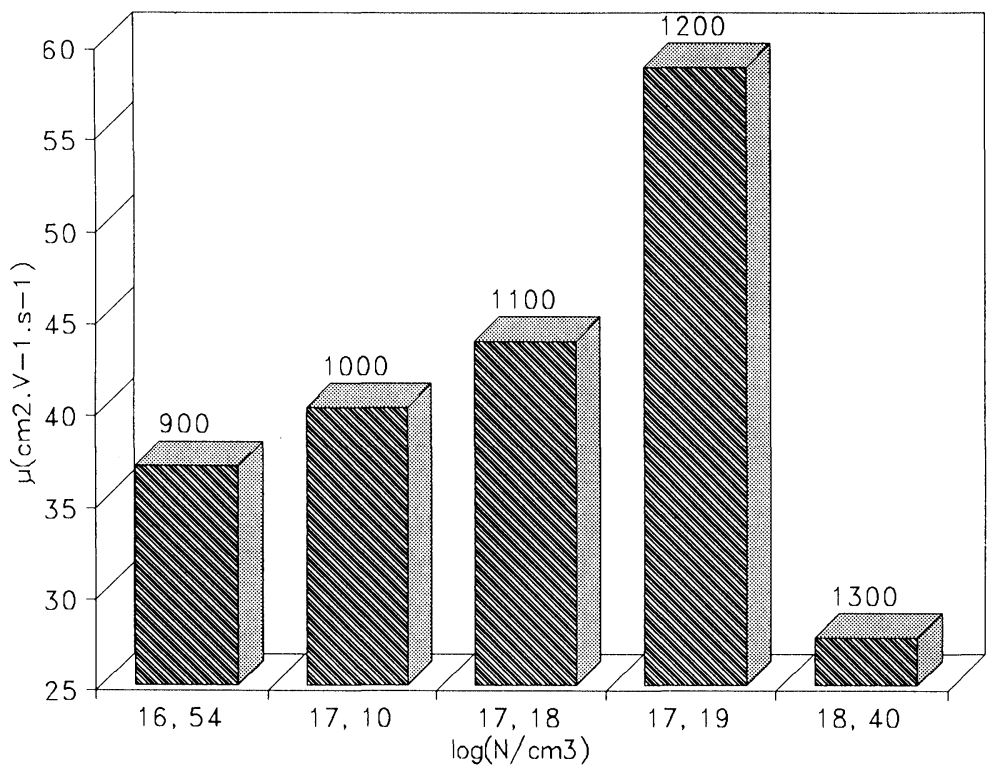

FIGURE 2 Mobility versus carrier concentration for $\operatorname{In}_{2} \mathrm{O}_{3}$ ceramics sintered at various temperatures $\left({ }^{\circ} \mathrm{C}\right)$.

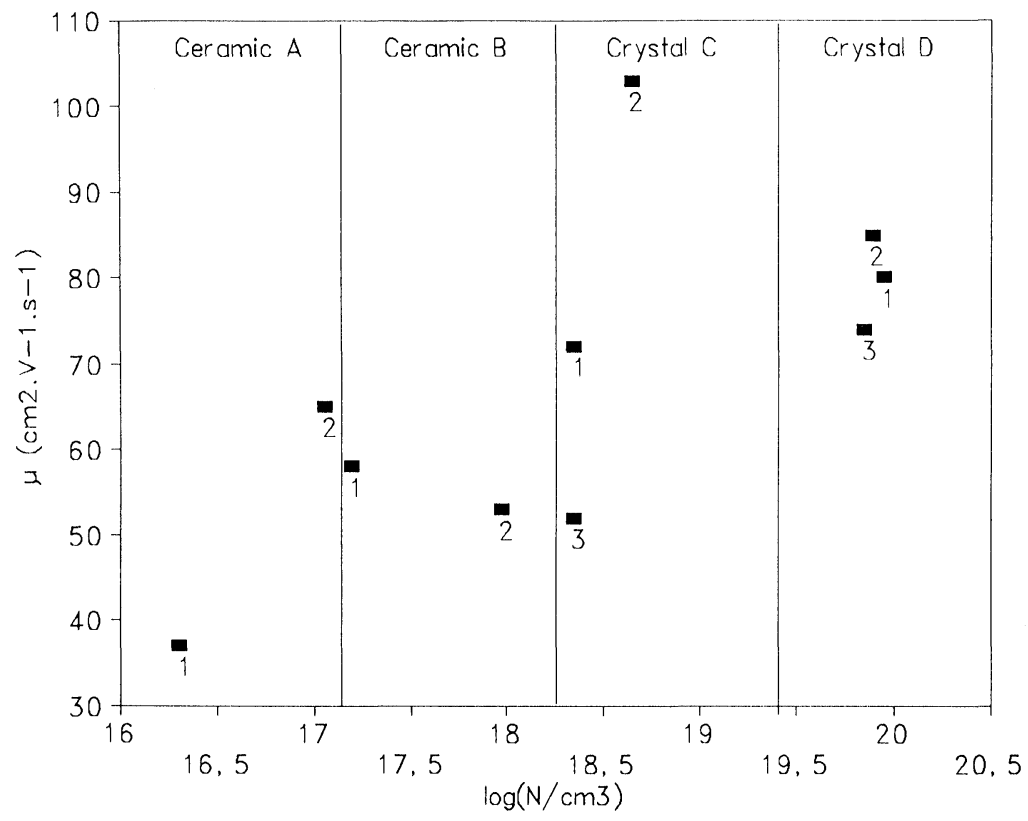

FIGURE 3 Mobility versus carrier concentration for $\operatorname{In}_{2} \mathrm{O}_{3}$ (ceramics A sintered at $900^{\circ} \mathrm{C}$ and $\mathrm{B}$ sintered at $1200^{\circ} \mathrm{C}$; single crystals $\mathrm{C}$ ) and $\mathrm{Sn}$ doped $\mathrm{In}_{2} \mathrm{O}_{3}$ single crystal $\mathrm{D} ; 1$ untreated, 2 treated under vacuum, 3 treated under oxygen. 
Indium Oxide is reduced more easily at high temperature than at low temperature.

$$
\mathrm{In}_{2-\varepsilon}^{3+} \mathrm{In}_{2}^{3+} \mathrm{O}_{3} \longrightarrow \mathrm{In}_{2}^{3+} \mathrm{O}_{3-\varepsilon^{\prime \prime}}\left[\mathrm{e}^{-}(\mathrm{CB})\right]_{2 \varepsilon^{\prime \prime}}+\frac{\varepsilon^{\prime \prime}}{2} \mathrm{O}_{2}
$$

The mobility, $\mu$, and carrier concentration, $\mathrm{n}$, increase with the sintering temperature from $1000^{\circ} \mathrm{C}$ to $1200^{\circ} \mathrm{C}$ (Fig. 2). In the small carrier concentration case, if we suppose that the scattering mechanism is mainly the ionized impurity centers, then $\langle\tau\rangle$ decreases as the carrier concentration increases. Therefore, the mobility also decreases or is constant in the degenerate case as the carrier concentration increases since $\mu=\mathrm{q}\langle\tau\rangle / \mathrm{m}^{*}$. If we suppose that the scattering mechanism is mainly the phonons, then $\langle\tau\rangle$ is constant as the carrier concentration increases, therefore, the mobility remains unchanged or decreases in the degenerate case as the carrier concentration increases. However, in our case, that does not occur. It would rather imply that the "active oxygen vacancies" associated states have to be linked to extended conduction band states (modification of the conduction band edge) causing a lowering of the carrier effective mass $\mathrm{m}^{*}$ and an increase in the mobility (see also below).

In fact, the highest carrier mobility value $\left(\mu=58 \mathrm{~cm}^{2} \cdot \mathrm{V}^{-1} \cdot \mathrm{S}^{-1}\right)$ obtained for $\mathrm{In}_{2} \mathrm{O}_{3}$ ceramics corresponds to a carrier concentration of about $\mathrm{n}=1.54 \times 10^{17}$ $\mathrm{cm}^{-3}$ (Fig. 2). For higher values, the concentration of the induced-doping lattice defects is large enough so that they can interact with the conduction band electrons. In this case, the mobility decreases with the carrier concentrations, i.e., the mechanism of ionized impurity scattering becomes more important so as to induce a decrease of relaxation time $\langle\tau\rangle$.

Fig. 3 illustrates the influence of heat treatment in various ambients on the transport properties for $\operatorname{In}_{2} \mathrm{O}_{3}$ ceramics (A and B) and for $\operatorname{In}_{2} \mathrm{O}_{3}(\mathrm{C})$ and $2 \% \mathrm{Sn}$ doped $\mathrm{In}_{2} \mathrm{O}_{3}$ (D) single crystals.

When no annealing treatment has been undertaken, ceramic sample $\mathrm{A}$, sintered at $900^{\circ} \mathrm{C}$ (Fig. 3), exhibits rather low values of carrier concentration $\left(\mathrm{n}=2 \times 10^{16}\right.$ $\left.\mathrm{cm}^{-3}\right)$ and mobility $\left(\mu=37 \mathrm{~cm}^{2} \cdot \mathrm{V}^{-1} \cdot \mathrm{S}^{-1}\right)$; they are highly enhanced by the annealing procedure under vacuum $\left(1.1 \times 10^{17} \mathrm{~cm}^{-3}\right.$ and $65 \mathrm{~cm}^{2} \cdot \mathrm{V}^{-1} \cdot \mathrm{S}^{-1}$ respectively). These results corroborate those shown in Fig. 1 and 2, previously discussed, where it was observed that the carrier concentration and the mobility increased with the sintering temperature. The values of concentration and mobility for sample A-2 treated under vacuum are close to those obtained for the sample sintered at the temperature about $1200^{\circ} \mathrm{C}$ (Fig. 1 and Fig. 2). These results confirm the above hypothesis that the electronic states corresponding to the lack of oxygen ("active oxygen vacancies") in the degenerate n-type semiconductor are mixed with electronic states of the conduction band, which is predominantly formed by the In $(5 s, 5 p)$ orbitals. As the carrier concentration increases under vacuum, the delocalization of the electron responsible for the conductivity is enhanced probably due to a lowering of the effective electron mass (increase of $\mu$ ) reported above.

On the other hand, the annealing treatment under vacuum performed on sample $\mathrm{B}$, sintered at $1200^{\circ} \mathrm{C}$, induces a decrease in $\mu$, although $\mathrm{n}$ increases (Fig. 3). This result is also in agreement with those reported in Fig. 2, where it is shown that the 
mobility decreases as the carrier concentration increases, for samples sintered at temperature higher than $1200^{\circ} \mathrm{C}$. This phenomena has been discussed above.

For single crystals, the rather high density of carriers occurring for $\operatorname{In}_{2} \mathrm{O}_{3}$ (sample $\mathrm{C}$ in Fig. 3), even for the non-thermally treated sample $\left(\mathrm{n}=2.4 \times 10^{18} \mathrm{~cm}^{-3}\right)$, should also be correlated to the large density of "active oxygen vacancies". For $2.5 \%$ mol Sn-doped $\operatorname{In}_{2} \mathrm{O}_{3}$ (sample D), the high density of the carrier concentration $\left(\mathrm{n}=2.4 \times 10^{20} \mathrm{~cm}^{-3}\right.$, Fig. 3) is of the same order of magnitude as the $\mathrm{Sn}$ concentration ${ }^{11}$, so that the electron concentration arising from the "active oxygen vacancies" can be neglected ${ }^{12}$. For both single crystals $C$ and $D$, the carrier mobility also depends on the thermal treatment; indeed $\mu$ decreases after heating the samples under oxygen pressure and increases after heating under vacuum (this phenomena is particularly noticeable for sample C) (Fig. 3).

All these investigations (on IO and ITO ceramics and single crystals) lead us to set up the following "physical" and "chemical" models:

1) Physical model:

The Fermi level in the conduction band is located at the same energy as those of the states attributed to the "active oxygen vacancies". Only the electrons located near the Fermi level contribute significantly to the mobility. Consequently, a small change in the density of states of oxygen vacancies near the Fermi level induced by a treatment under oxygen pressure or vacuum can significantly modify the carrier mobility without drastically changing the carrier concentration. High oxygen pressure treatment decreases a part of oxygen vacancies; as a consequence the overlapping of corresponding wave function diminishes leading to a higher localization. The treatment under vacuum will provoke the opposite situation (Fig. 4). On the other hand, we know that the solubility limit of $\mathrm{Sn}$ in $\mathrm{In}_{2} \mathrm{O}_{3}$ is about $1 \%{ }^{11}$. So in the case of $\mathrm{Sn}$-doped $\operatorname{In}_{2} \mathrm{O}_{3}$ during the oxygen pressure treatment, we cannot neglect the influence of the formation of the neutral $\left(\mathrm{Sn}_{2} \mathrm{O}_{4}\right)^{\mathrm{x}}$ complex which perhaps is favored. Although this complex does not contribute to the electron concentration, its presence can decrease the mobility by a neutral scattering process.

2) Chemical model:

It has been stated above for IO ceramics, that degeneracy occurs even for carrier concentrations that are not very high $\left(\approx 10^{16}-10^{17} \mathrm{~cm}^{-3}\right)$. On the other hand, rather high mobilities are observed $\left(\approx 35-40 \mathrm{~cm}^{2} \cdot \mathrm{V}^{-1} \cdot \mathrm{S}^{-1}\right)$. This would imply that the interactions between the conduction-band electrons and the ionized donor centers $\mathrm{V}_{0}$ and $\mathrm{V}_{0}^{-}$are very weak $\left(\mathrm{V}_{0}\right.$ and $\mathrm{V}_{0}^{-}$originate from the ionization: $\mathrm{V}_{0}^{2-} \rightarrow \mathrm{V}_{0}^{-}+\mathrm{e}^{-}$and $\mathrm{V}_{0}^{-} \rightarrow \mathrm{V}_{0}+\mathrm{e}^{-}$; here $\mathrm{V}_{0}^{2-}$ symbolizes, within the frame of the ionic model, the "active oxygen vacancy".

Under these circumstances one would conclude that the ionization energy falls to zero, i.e., the impurity band merges with the conduction band.

We are dealing here with a situation rather different than that accounting for the electrical behavior of more conventional (3d) n-type semiconductors, such as $\mathrm{T}_{\mathrm{i}} \mathrm{O}_{2-\mathrm{x}}, \mathrm{S}_{\mathrm{r}} \mathrm{T}_{\mathrm{i}} \mathrm{O}_{3-\mathrm{x}}$, for which the donor centers are located at a few tenths of an eV $\left(0.1-0.5 \mathrm{eV} \text { ) below } \mathrm{E}_{\mathrm{c}} \text { (for } \mathrm{n} \text { ranging between } 10^{16}-10^{19} \mathrm{~cm}^{-3}\right)^{14}$. 

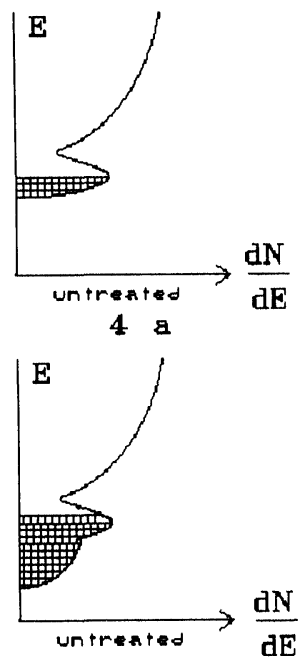

$4 \mathrm{c}$
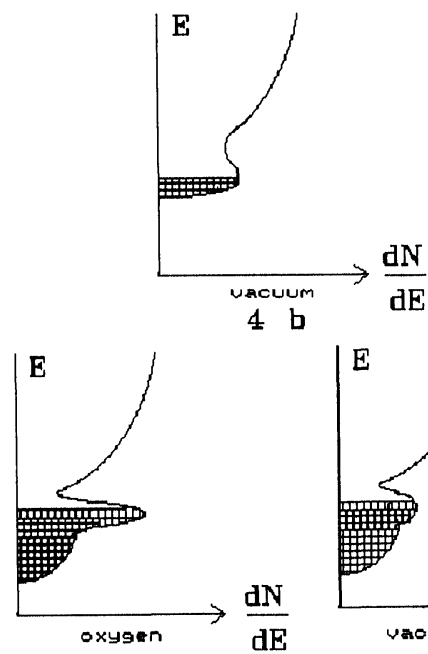

$4 \mathrm{~d}$

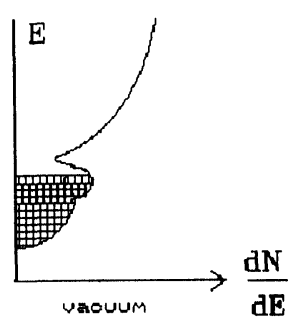

4 e

FIGURE 4 Schematic energy band diagrams for $\operatorname{In}_{2} \mathrm{O}_{3}$ and $\mathrm{Sn}$ doped $\operatorname{In}_{2} \mathrm{O}_{3}$ untreaded, treated under vacuum or under oxygen pressure; $4 \mathrm{a}, 4 \mathrm{~b}$ : pure $\operatorname{In}_{2} \mathrm{O}_{3} ; 4 \mathrm{c}, 4 \mathrm{~d}, 4 \mathrm{e}$ : Sn doped $\operatorname{In}_{2} \mathrm{O}_{3}$.

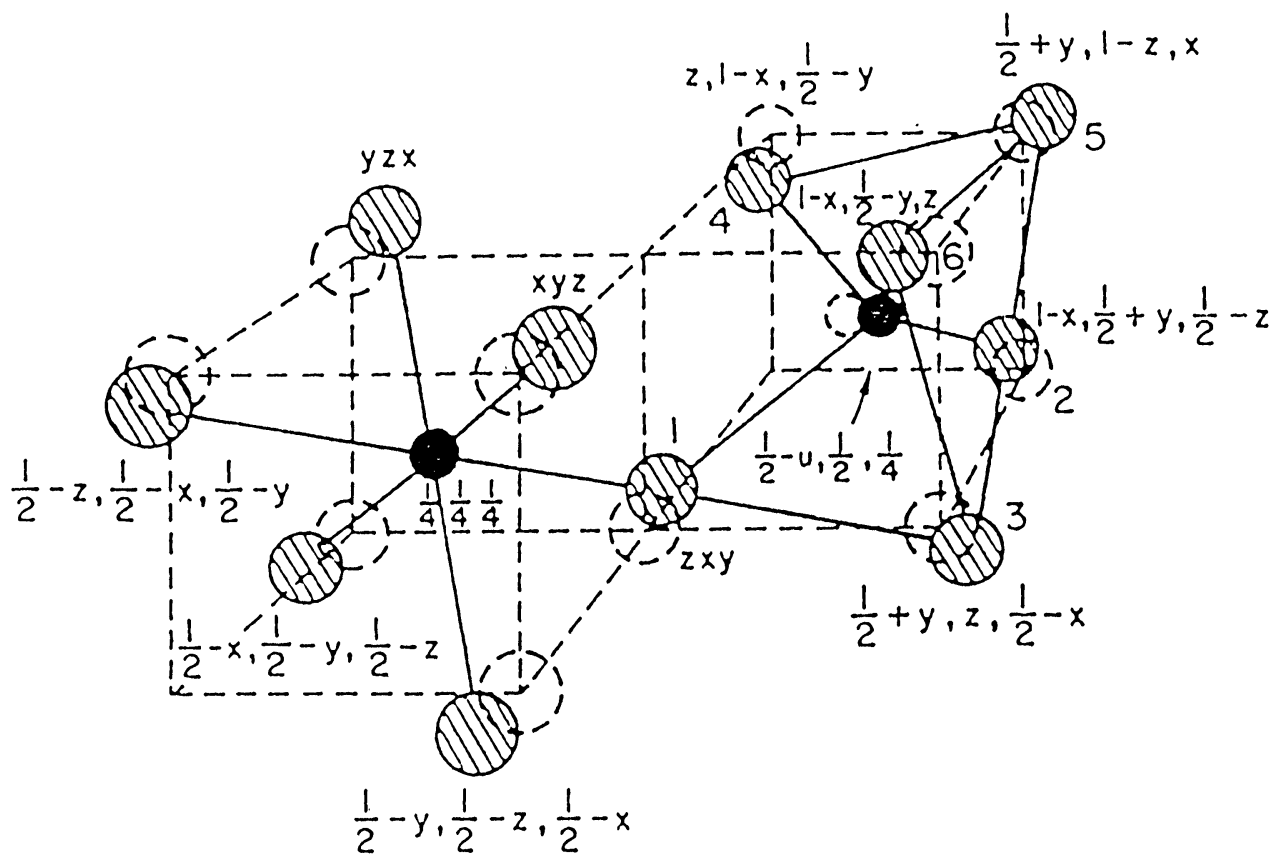

FIGURE 5 Representation of IO bixbyite structure. 
Besides, rather similar situation occurs for (s,p) n-type semiconductors not having the bixbyite structure, such as $\mathrm{SnO}_{2-\mathrm{x}}$. For IO (ITO) which has the bixbyite structure, it would appear that the possible screening (with regard to the cations) of the oxygen vacancies (position 5) by the oxygen located nearer to the cations in positions 2, 4, and 6 (Fig. 5), would account for the peculiar electrical behavior. ${ }^{6}$

\section{REFERENCES}

1. K.L. Chopra, S. Major and D.K. Pandya, Thin Solid Films, 1021 (1983) 1-46.

2. I. Hambery and C. Granquist, J. Appl. Phys. 60 R 1231 (1986) 11.

3. H. Hoffman, A. Dietrich, J. Pickl and D. Krause, Appl. Phys. 161 (1978) 381.

4. W.G. Hains and R.H. Bube, J. Appl. Phys. 491 (1978) 304.

5. A.J. Steckl and G. Mohammed, J. Appl. Phys. 511 (1980) 3890.

6. C. Geoffroy, Thesis, University of Bordeaux (1990).

7. Z.M. Jarzebski and J.P. Marton, J. Electrochem. Soc. 1231, (1976) 199.

8. C.G. Fonstad, A. Linz and R.H. Rodiker, J. Electrochem. Soc. 1161 (1969) 1205.

9. J.A. Marley and J.C. Mac Acry, J. Appl. Phys. 441 (1973) 4618.

10. H. Haitjema and J. Elich, Solar Energy Mater. 161 (1987) 79.

11. Shi-jie Wen, G. Couturier, J. Portier, J.P Chaminade, J. Claverie. Mat. Science and Eng. B (to be published).

12. G. Frank, H. KÖstlin, Appl. Phys. A, 197 (1982).

13. V. Marfoing, photoconductivity, photo electric Effects, Handbook of semiconductors (North Holland) Vol. 2 (1980).

14. G. Campet, G. Geoffroy, J.P. Manaud, J. Portier, Z.W. Sun, J. Salardenne and P. Keou. Mat. Science and Eng. B 8, 45 (1991). 

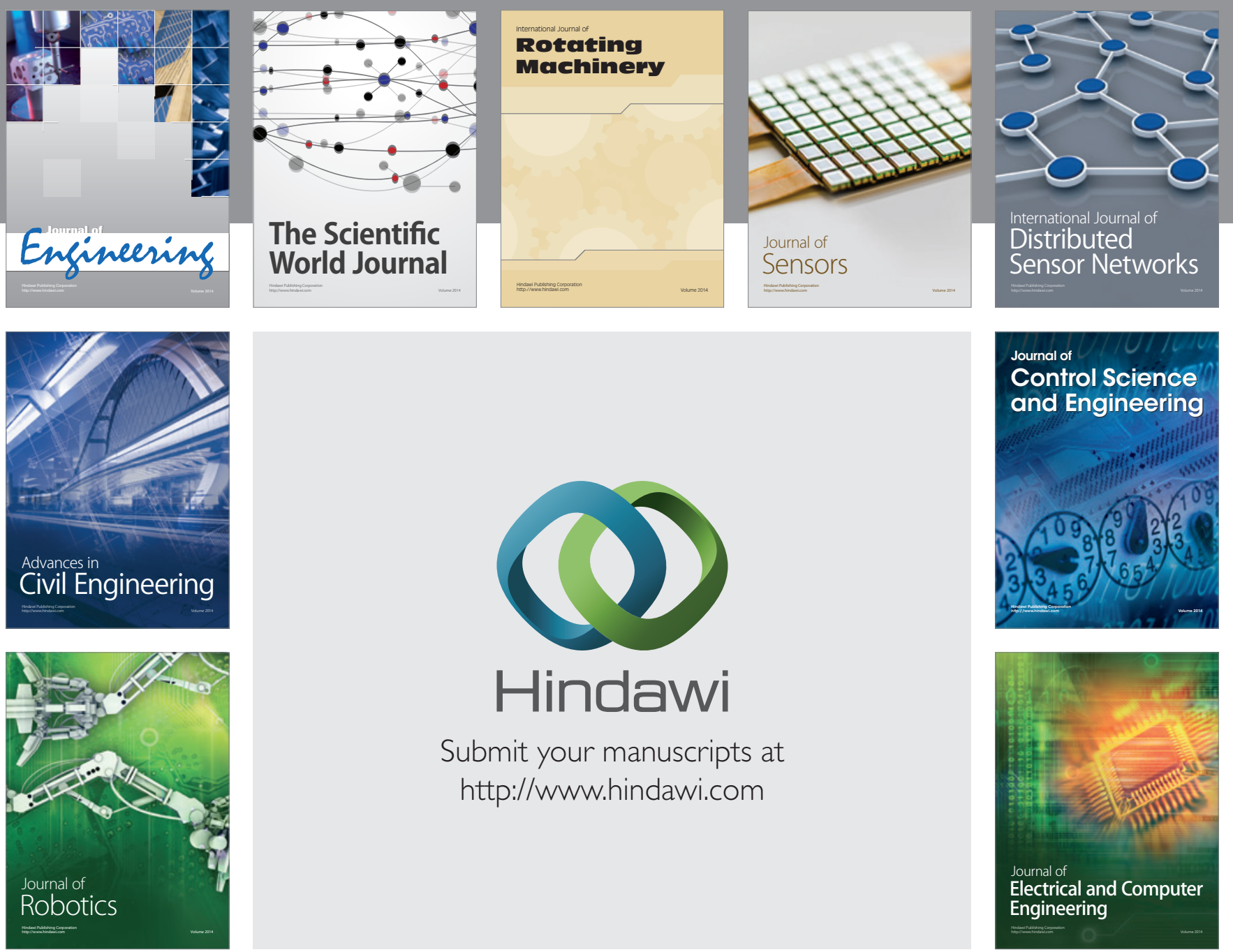

Submit your manuscripts at

http://www.hindawi.com
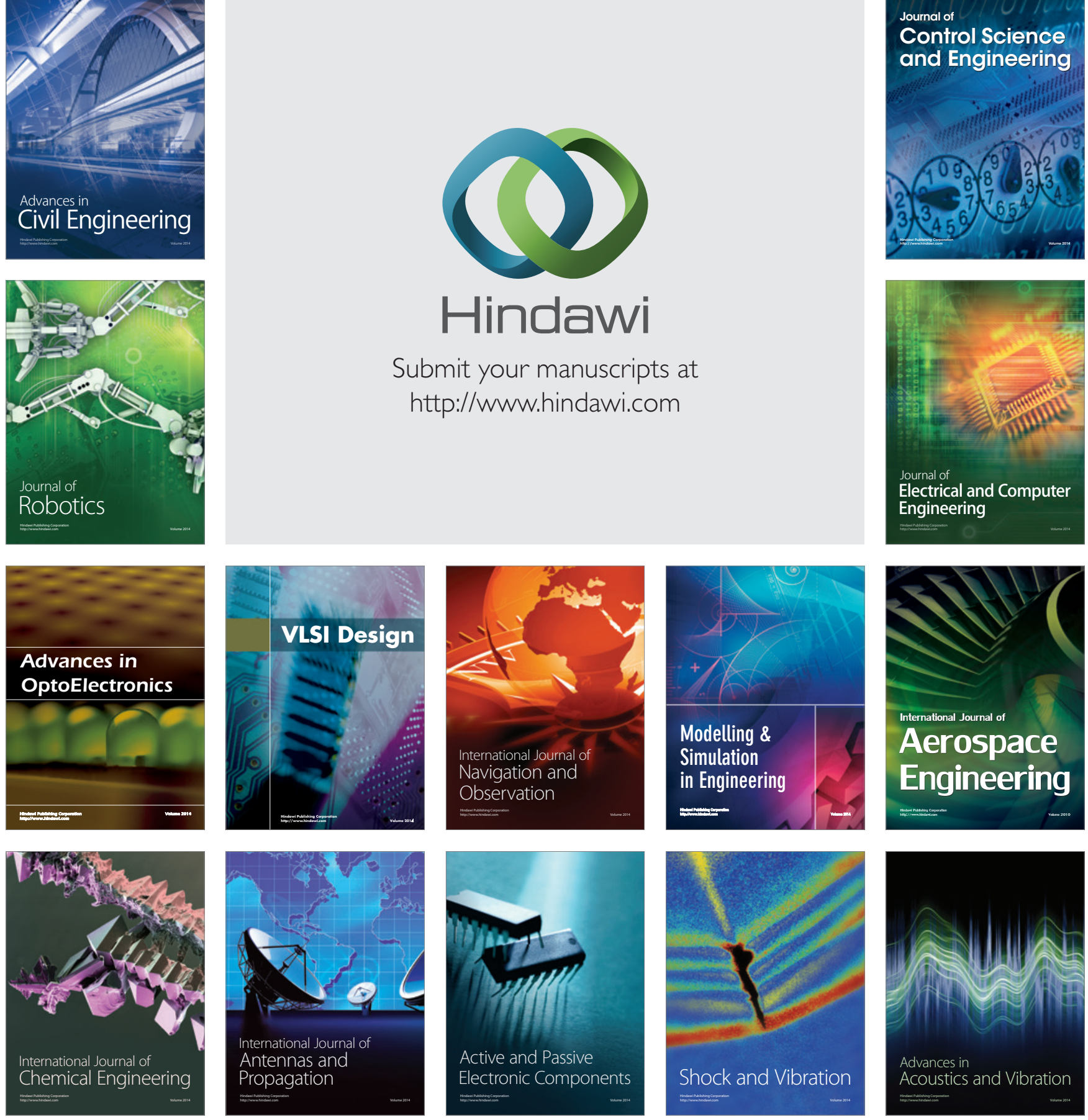